\title{
MODERNAS E IMAGINADAS. EL NACIONALISMO COMO OBJETO DE INVESTIGACIÓN HISTÓRICA EN LAS DOS ÚLTIMAS DÉCADAS DEL SIGLO XX
}

\author{
por \\ JOSÉ M. FARALDO \\ Universidad Europea Viadrina (Frankfurt/Order)
}

RESUMEN: El artículo repasa la producción historiográfica reciente sobre el nacionalismo, haciendo bincapié en el mundo anglosajón y en los nuevos trabajos de Europa Centrooriental. En el contexto del paradigma teórico general del nacionalismo se examinan las corrientes modernistas, el posmodernismo y los estudios culturales y las tendencias del etnosimbolismo.

Palabras Clave: Historiografía. Nacionalismo. Teorías de la modernización. Postmodernismo. Estudios culturales.

ABSTRACT: The article presents an overview of the recent historical literature about nationalism, focusing on the English-speaking world and the new researches from Central and East Europe. The modernist approach, the postmodern and cultural studies, the ethno-symbolical tendencies are reviewed in the context of the general theoretical paradigm of nationalism.

KEY WORDS: Historiography. Nationalism. Modernization theories. Postmodernism. Cultural studies.

El análisis científico del nacionalismo ${ }^{1}$ se ha convertido hoy día en una verdadera disciplina, con sus clásicos y libros canónicos, sus innovadores y enfants

${ }_{1}^{1}$ Bibliografías sobre el tema se pueden encontrar en WINKLER, Heinrich A. /SCHNABeL, Thomas Bibliographie zum Nationalismus, Göttingen 1979, BENTLEY, Gerald Carter: Ethnicity and Nationalism: A Bibliography Guide, Seattle 1981, y en ROSSBACH, Udo /BOERNER, Peter: «Bibliography»: Boerner, P. (Ed.): Concepts of National Identity Baden-Baden 1986. Repaso a las teorías gene- 
terribles, sus revistas, congresos, conferencias y asociaciones. Existen centros e institutos dedicados exclusivamente a la investigación en torno al tema, se editan series de libros, se diseñan páginas web y la difusión académica de estos resultados ocupa cátedras y cursos a lo largo de todo el globo. Hasta el punto de que podría decirse que, en realidad, el estudio de pocos problemas se halla tan internacionalizado como el del nacionalismo.

Se trata también de una de las preocupaciones científicas en las que más activamente se practican la inter- y la transdisciplinariedad. Aunque casi cada enfoque se ve en la obligación de guardar en algún modo las maneras historicistas, abundan las intromisiones de la ciencia económica, la sociología, la estética, la antropología, la folklorística, la geografía humana, la psicología, el derecho y hasta las ciencias deportivas.

En este artículo vamos a intentar bosquejar las líneas de investigación del tema más importantes entre los años 1980 y 2000 , centrándonos sobre todo en la perspectiva historiográfica. Las dos últimas décadas del siglo veinte parecen haber sido excepcionalmente fructíferas a la hora de analizar el fenómeno -en paralelo a su resurgir como realidad histórica. Aunque se ha publicado una extensa serie de obras clave y una aún más extensa selva de monografías y estudios concretos, no todas ellas son fáciles de clasificar. La propia naturaleza del fenómeno ha obligado a análisis en el límite de varias disciplinas y a veces, como en las obras de Gellner, Smith o Connor, no se sabe donde termina la historiografía y donde empiezan la sociología, la antropología o la politología. Por esa razón vamos a considerar aquí tambien las obras no exclusivamente históricas cuya importancia haya sido sin embargo esencial para la disciplina del estudio de los nacionalismos.

Hay que hacer resaltar, sin embargo, que en un mundo como el de hoy en el que la educación de masas y el desarrollo de los medios de comunicación ha centuplicado la producción intelectual, «las generalizaciones sobre disciplinas académicas requieren audacia»². Una búsqueda en el catálogo on-line de una biblioteca cualquiera bajo la palabra «nacionalismo» arroja varios cientos —quizá mi-

rales en torno al nacionalismo en SMITH, Anthony. D.: Theories of Nationalism, Londres $1983,2^{\mathrm{a}} \mathrm{Ed}$., [Ed. española en SMITH, Anthony, Teorias del nacionalismo Barcelona 1976 (Basada en la ed. de 1971, Theories of Nationalism Londres)], BLAS GUERRERO, Andres de: Nacionalismo e ideologías politicas contemporáneas, Madrid 1984 y LlOBERA, Josep R.: Recent Theories of Nationalism, Work paper $\mathrm{n}^{\circ} 164$, Barcelona 1999. Aunque sólo para referencias, merece la pena prestar atención a SNYDER, Louis L.: Encyclopedia of Nationalism Nueva York 1990. Algunas selecciones de textos, todas ellas con excelentes comentarios e introducciones (en especial el primero, casi un intento de teoría general del nacionalismo) ELEY, Geoff / SUNY, Ronald Grigor (Eds.): Becoming National. A reader, Nueva York 1996 [desde la perspectiva de Cultural Studies]; HUTCHINSON, John / SMITH, Anthony (Eds.): Nationalism, Oxford 1996 [desde la perspectiva del etnosimbolismo] y WOOLF, Stuart (Ed.): Nationalism in Europe. 1815 to the present, Londres 1996 [desde una perspectiva más académica].

2 JACOBI, Russell: «A new intellectual history?» en FOX-GENOVESE, Elizabeth / LASCH-QUINN, Elizabeth (Eds.): Reconstructing History. The Emergence of a New Historical Society, Nueva York / Londres 1999, pp. 94-118, aquí p. 94.

Hispania, LXI/3, núm. 209 (2001) 933-964 
les- de libros como resultado; una bibliografía en cd-rom en la que estén indexadas un determinado número de publicaciones periódicas del ámbito anglosajón ofrece centenares de artículos por año. Y, teniendo en cuenta que Internet, la fotocopiadora, el préstamo interbibliotecario y las instituciones de venta de copias de artículos ofrecen la posibilidad de hacerse con los materiales de ese flujo intelectual ¿cómo pues valorar todo ello? Resulta físicamente imposible leer y analizar toda la producción historiográfica directa sobre el nacionalismo, no digamos ya aproximaciones laterales, como «identidad», «etnia», «autarquía económica», etc... Aún más: ¿cómo generalizar el estado de la cuestión sin tener en cuenta el cada vez más pujante Oriente intelectual, los teóricos indios del poscolonialismo, las nuevas aproximaciones japonesas, el análisis de las universidades sudafricanas?

$\mathrm{Al}$ mismo tiempo, en un mundo progresivamente más complejo y más plural, la valoración de una aportación intelectual acaba por producirse muchas veces gracias a un cierto azar, mezclado a su vez con factores por completo ajenos al valor de la propia obra. Así, el mero hecho de haber sido publicada en una lengua relativamente marginal ha hecho pasar desapercibido en el mundo intelectual una, a nuestro juicio, temprana innovación deconstructivista sobre el tema, escrita por el valenciano Joan F. Mira ${ }^{3}$. Del mismo modo una editorial académica, el alemán como lengua y una terrible presentación sellaron probablemente el destino de otra original obra, desde el campo un tanto olvidado de la psicología, el «nación como forma», de Dirk Richter ${ }^{4}$.

Llegados a este punto, comprobamos que el número de veces que un libro aparece citado en las obras de otros colegas no constituye certificado de calidad, sino prueba de la posibilidad que han tenido de acceder a ella. Los milieus científicos continúan conformando la base de la discusión — virtual y real- de problemas y del acceso a obras sancionadas como inevitables. Se trata generalmente de la propia universidad y del espacio de comunicación entre centros científicos y educativos, publicaciones y conferencias, casi siempre de ámbito estatal, pero también las redes de enlace con otros centros, en otros estados o ámbitos. Cada vez más, sin embargo, los nuevos medios y las nuevas posibilidades de comunicación permiten la creación de identidades investigadoras propias, en las que el científico individualmente elige de entre las innumerables aportaciones, aquellas que considera adecuadas $\longrightarrow$ a las que tiene acceso - . Ello produce por un lado el fenómeno de un extrañamiento en las referencias: se citan cosas que la mayoría no conoce y de las que incluso, en un principio, se desconfía.

Un segundo fenómeno es que se ha formado progresivamente un espacio científico internacional pero que, en realidad, no es otro que el espacio anglosajón, dominador por potencia editorial, investigadora y, sobre todo, lingüística. Este espacio supone la referencia esencial a la hora de debatir y discutir, margi-

3 Mira, Joan F.: Crítica de la Nació Pura, Valencia 1984

${ }^{4}$ RICHTER, Dirk: Nation als Form, Opladen 1996. 
nando a otros espacios u obligándolos a integrarse en él. Así, por poner el ejemplo más cercano, los importantes trabajos sobre nacionalismo realizados en las universidades españolas durante las dos últimas décadas ${ }^{5}$ parecen haberse quedado aislados y sin dar todos los frutos posibles. Sólo un puñado de ellos que han sido traducidos o producidos ya en instituciones anglosajonas ${ }^{6}$ o citados por anglosajones estudiosos de temas españoles, han recibido suficiente atención en la literatura científica internacional.

De este modo, quien quiera convertir estos fragmentos - monografías y artículos - en una narración con aspecto coherente deberá ser consciente de que dicha narrativa resultará sólo una de las posibles, producto de decisiones concretas o de azares y por ello siempre falsa o mejor dicho, parcial, partidaria. Un historiador honesto debiera siempre comenzar trazando los límites entre los que se va a encuadrar su aportación, en lugar de, como resulta habitual, esconder tras la retórica de una supuesta coherencia expositiva las deficiencias inevitables de su análisis. Por ello, creemos conveniente empezar marcando nuestras lindes: este artículo se centrará en las producciones intelectuales de esa república de los sabios virtual que es el mundo anglosajón, con ligeras desviaciones a las posiciones centroeuropeas - con preferencia por las de lengua alemana, que, por otro lado, presentan una cada vez mayor sintonía, al menos en este aspecto, con las anglófonas. Hemos evitado referencias a producciones españolas - e hispánicas en general- así como a ciertas obras de temas españoles publicadas en inglés, por parecernos que el lector español ya debe de estar familiarizado con ellas. Nos ocuparemos sobre todo de publicaciones en forma de libro, aunque tengamos que dejar de lado algunos trabajos que, aparecidos como artículos, han sido sin embargo enormemente influyentes.

\section{PRIMER NIVEL: EL NUEVO CONSENSO}

En el prefacio a uno de los dos libros póstumos de Ernest Gellner ${ }^{7}$, el hijo de éste relata la sorpresa del filósofo cuando «Nations and nationalism», un libro para él entonces no excesivamente importante, se convirtió en su obra más vendida y traducida ${ }^{8}$. David N. Gellner atribuye esta repentina popularidad al renovado interés sobre el tema, producido con seguridad por los aconte-

\footnotetext{
5 El mejor recuento de la bibliografía sobre el tema - aunque queda sin revisar la década de los noventa, quizás la más importante- es NúÑEZ SEIXAS, Xosé M.: Historiographical Approaches to Nationalism in Spain, Saarbrücken 1993. Algunas referencias más recientes en HERNANDEZ SANDOICA, Elena: «La historia contemporánea en España: Tendencias recientes» en Hispania LVIII/1, num. 198 (1998): 65-95, especialmente 92-93.

${ }^{6}$ El ejemplo más claro es Josep R. LlObera (véase The God of Modernity. The development of nationalism in western Europe, Oxford 1994)

7 GELLNER, Ernest: Nationalism, Londres 1997.

8 GELLNER, E.: Nations and Nationalism, Oxford 1983.
} 
cimientos políticos —en Europa, el surgimiento de los regionalismos y nacionalismos de los años setenta y luego las conmociones en los países del Este. Efectivamente, a partir de los primeros ochenta comenzaron a aparecer una serie de obras que no sólo supusieron una renovación radical de la disciplina, sino que además coincidían en llevar a cabo una cierta deconstrucción ${ }^{9}$ de lo que el fenomeno nacional era. Más allá de las diferencias - a veces profundas- entre los representantes de esta «nueva ola» de estudios sobre el nacionalismo, se llegó con el paso del tiempo a la creación de un cierto consenso en el análisis que se asentó definitivamente hacia principios de la década de los noventa ${ }^{10}$.

La genealogía de este consenso - relacionado a su vez con las teorías de la modernización ${ }^{11}$ — se puede iniciar con los trabajos de Hans Kohn ${ }^{12}$, a partir de los años veinte y treinta ${ }^{13}$, en los que, sin duda con cierta influencia marxiana, mostraba al nacionalismo como un producto de la globalización del mundo moderno ${ }^{14}$. La teoría de Karl Deutsch del nacionalismo como comunicación social, relacionado por ello con el proceso modernizador, supuso una aportación importante en los años cincuenta, siendo posteriormente un tanto postergada y por fin, hoy día, parece estar siendo revisada con provecho ${ }^{15}$. No tan decisivo pero no menos importante —entre otras cosas porque sirvió como objeto de

9 Utilizamos el término «deconstrucción» en un sentido etimológico, más que puramente derridiano.

${ }^{10} \mathrm{~A}$ mi juicio la más importante manifestación de la cristalización de dicho consenso fue el congreso internacional «Nacionalismos en Europa. Pasado y Presente» celebrado en Santiago de Compostela en 1993. Las actas del congreso ofrecen una excelente recapitulación del estado de la cuestión por aquel entonces Beramendi, Juan G./ MÁrz, Ramón / NúÑEZ, Xosé M.: Nationalism in Europe. Past and Present. 2 Vols., Santiago de Compostela 1994.

11 Una sucinta revisión de dichas teorías, otorgando importancia principal al «retorno» de las últimas décadas en GöTZ, Norbert "Die Modernisierungstheorien schlagen zurück. Diskussionsstand, kulturwissenschaftliche Anwendung und das Beispiel des Nationalismus» en HENNINGSEN, Bernd / SCHRÖDER, Stephan Michael (Eds.): Vom Ende der Humboldt-Kosmen. Konturen von Kulturwissenschaft, Baden-Baden 1997, pp. 151-173.

12 Aunque en los últimos tiempos se ha subrayado la figura precursora de Ernest Renan y su «Qu' est-ce qu'une nation?» (1882). Cf. ELEY/SUNY (Eds.): Becoming national... o el más tarde citado Homi K. Bhabha.

${ }_{13}$ Me gustaría llamar la atención sobre su excelente trabajo en torno a la Unión Soviética que ha pasado desapercibido y que, sin embargo, presenta una a mi juicio temprana visión constructivista del tema [KoHN, Hans: Der Nationalismus in der Sowjetunion, Frankfurt/Main 1932]. Por otro lado véase su clásico The Idea of Nationalism publicado en Nueva York en 1944 [en castellano: La idea del nacionalismo. Mexico 1949].

${ }_{14}$ De hecho, para Kohn, el mundo moderno supone «la edad del nacionalismo» [The Age of Nationalism, Londres 1962]

is Cf. DeutsCH, Karl: Nationalism and Social Comunication, Nueva York 1963, ibid. Nationalism and Its Alternatives, Nueva York 1969, o ibid. Nationenbildung - Nationalstaat - Integration Düsseldorf 1972. Para la revisión WEISER, Thomas: «K.W. Deutschs Modell der Nationswerdung und sein Beitrag für die historische Nationalismusforschung» en SCHMIDT-HARTMANN, Eva, (Ed.): Formen des nationalen Bewußtseins in Lichte zeitgenössischer Nationalismustheorien, Munich 1994, pp. 127-143. 
discusión de Ernest Gellner- se encuentra también el clásico análisis de Elie Kedourie $^{16}$, en el que presentaba al nacionalismo exclusivamente como ideología - inventada en Europa en el siglo XIX - y que como tal era objeto de crítica y tachada de «accidente» en el camino del progreso humano.

La idea de que el nacionalismo era un fenómeno de aparición histórica reciente -algo que contradecía las tesis esencialistas mantenidas por la historiografía nacional decimonónica- permeaba también estos análisis. La causalidad de esta aparición se buscaba en el impacto de la revolución francesa y en la filosofía romántica alemana, manteniéndose siempre en un contexto de historia de las ideas. Contra ese «intelectualismo» se rebeló Ernest Gellner, desarrollando una visión propia que se ha convertido -incluso con sus enormes problemas y carencias - en la teoría del nacionalismo que supone hoy día el fondo contra el que cualquier alternativa debe definirse a su vez.

Gellner cuenta que el libro de Kedourie - quien era por entonces su amigo y colega - le «despertó» de su asumida creencia en el «naturalismo» o la esencialidad del nacionalismo ${ }^{17}$. Sin embargo él no estaba de acuerdo en considerar el problema como algo marginal a la historia humana. Al contrario, Gellner intuía que se trataba de un fenómeno, quizá pasajero, pero en cualquier caso, necesario al desarrollo del mundo moderno.

La primera versión de su teoría del nacionalismo apareció en el influyente capítulo siete de su «Pensamiento y cambio» ${ }^{18}$. La reelaboración de sus ideas años más tarde, en el ya citado "Naciones y Nacionalismo», (publicado, como hemos dicho en 1983) daría lugar al establecimiento del «modernismo» - la tesis de que el nacionalismo surge con la modernidad - como tesis de consenso. Gellner desarrolló su pensamiento sobre el tema a lo largo de varios de sus muchos libros ${ }^{19} \mathrm{y}$, al final de su vida, se trasladó a Praga, donde fundó un centro de estudios del nacionalismo. El último libro que terminó antes de morir -y que fue publicado póstumamente- supone el más acabado compendio de su teoría que jamás escribiera ${ }^{20}$.

Gellner partía, para su análisis del nacionalismo, de una perspectiva general de la historia humana. La forma en que Gellner comprendía el nacionalismo estaba ligada a su comprensión de la diferencia entre la «sociedad agraria» y la «sociedad industrial» - algo que encontraremos de nuevo en Anthony Giddens-. En el mundo dominado por la sociedad agraria el nacionalismo no

16 KeDOURIE, Elie: Nationalism, Londres 1960.

17 GeLLNER, Nationalism, p.10.

18 Gellner, E., Though and Change, Londres 1964, pp. 147-178.

19 Además de los citados y, por poner unos ejemplos, «Scale and nation»: Philosophy of the Social Sciences Vol. 3 (1973)1-17; Plough, Sword and Book, Londres 1988; «Nationalism in Eastern Europe»: New Left Review 189 (1991) 127-136; (1995) Encounters with nationalism Oxford. Una excelente colección de análisis de su teoría del nacionalismo - incluyendo poderosas críticas - en HALL, John A.: The State of the Nation. Ernest Gellner and the Theory of Nationalism, Cambridge 1998.

${ }^{20} \mathrm{El}$ ya citado Nationalism.

Hispania, LXI/3, núm. 209 (2001) 933-964 
existía entre otras cosas porque los lazos culturales no suponían un lazo político, ni los lazos políticos requerían de una cultura similar ${ }^{21}$. En una sociedad agraria el estatus, la posición en la escala social, era el que marcaba las relaciones políticas, mientras que el lenguaje que se hablara resultaba algo secundario. Es sólo el proceso de modernización - que él parece confundir voluntariamente con la industrialización - el que permitirá que, a causa de las necesidades de la nueva sociedad (tendencia al igualitarismo, homogeneidad cultural, sistema de Estados...) surja el nacionalismo. Ello permite a Gellner definir el nacionalismo como «un principio político que mantiene que la cultura común es el lazo social básico" ${ }^{22}$. Lo cual no implica que ese principio político haya sido eterno. Con una de sus típicas frases lapidarias, que tan aptas son para convertirse en una cita, Gellner afirma que «la cultura y la organización social son perennes. Los estados y el nacionalismo no» ${ }^{23}$.

La modernidad del principio nacional es, por lo tanto, patente, pero su necesidad también, dado que la sociedad moderna es una sociedad donde el trabajo no es físico sino "semántico", es decir, depende de la habilidad para comprender y usar la información y la comunicación. Para que la sociedad industrial funcione hace falta una cierta homogeneidad cultural que sólo un sistema de educación general - estatal o, al menos de tendencia centralizadora- puede proporcionar. La concreta cultura elegida como medio de comunicación -el código de "alta cultura» que sumerje a toda cultura popular- se convierte entonces en un valor en sí mismo, un valor que puede —o debe, en la opinión de los nacionalistas - ser protegido.

El modelo general entonces sería:

«un orden agrario en el cual diferencias y matices culturales suponen un complejo sistema de estatus, pero no indican los límites de las unidades políticas, y otro, en el cual una masa anónima y móvil de participantes comparte la misma 'alta' cultura, relativamente libre de matices internos, pero ligada a las fronteras políticas de la unidad con la que se identifica» 24 .

El modelo que, como descripción del desarrollo histórico, es bastante correcto, se encuentra sin embargo con problemas a la hora de aclarar fenómenos nacionalistas en países de mayoría agraria. Asímismo - lo que es quizá más importante - resulta difícil explicar la presencia de discursos - y sentimientos- inequívocamente nacionalistas que algunos investigadores creen reconocer ya en la Antigüedad y, sobre todo, a partir de la Baja Edad Media.

\footnotetext{
21 GELLNER, Nationalism... p. 24.

22 Ibid. p. 3.

23 Ibid. p. 5.

${ }_{24}^{4}$ Ibid. p. 30.
} 
Pese a estas deficiencias - que el autor intentó corregir en sus últimas obras_-25, las tesis de Gellner son lo más cercano a una teoría global del nacionalismo que existe y no parece que muchas de sus tesis puedan ser rebatidas de momento. Los matices y reelaboraciones aportados por muchos autores - incluso los más críticos - no han conseguido desvirtuar el alcance general del modelo.

Si la infancia checa de Gellner tuvo un peso importante en la formación de su visión del nacionalismo ${ }^{26}$, resulta curioso que la segunda aportación importante al estudio del fenómeno que tomamos en cuenta, provenga también de Bohemia. Nos referimos a Miroslav Hroch quien ya en los años sesenta comenzó a producir algunos trabajos realmente innovadores, escritos en el contexto de la explosión de democracia - y de nacionalismo- de la Checoslovaquia de la primavera de Praga.

Sin embargo, los dos libros pioneros de $\mathrm{Hroch}^{27}$ permanecieron durante bastante tiempo como mera cita a pie de página de contados estudiosos anglosajones o centroeuropeos. De hecho, aunque se habían publicado tempranamente en alemán alguna de sus recapitulaciones sobre el tema ${ }^{28}$, sólo en los años ochenta, con la aparición de la edición inglesa de ambas obras ${ }^{29}$, ocuparon sus trabajos el lugar que merecían. Es importante referirse a los métodos de Hroch porque, de hecho, se trata de la parte más innovativa — sobre todo para la época- de su obra: la aplicación consciente del cuantitativismo al estudio de un problema para el que casi siempre se había utilizado un instrumental de historia de las ideas ${ }^{30}$. El enfoque de Hroch supuso la ruptura con una forma de análisis del nacionalismo que, al considerar a éste sobre todo una ideología, había emprendido su investigación con métodos clásicos, es decir, a base sobre todo de la descripción de producciones intelectuales: libros, artículos, folletos... Hroch, influído por el marxismo, comenzó a emplear las herramientas de la historia social y analizó sistemáticamente la composición social y la estructura de los movimientos nacionalistas en un determinado número de «naciones».

\footnotetext{
25 Véase su —ahora famosa- «Reply to Critics»: HALl, John A. / JARVIE, I. (Eds.): The Social Philosophy of Ernest Gellner, Amsterdam / Atlanta 1996.

${ }^{26}$ Él mismo lo admite en la citada «Reply...», por ejemplo.

$27 \mathrm{HROCH}$, Miroslav: Die Vorkampfer der nationalen Bewegung bei den kleinen Völkern Europas. Eine Vergleichende Analyse zur gesellschaftlichen Schichtung der patriotischen Gruppen, Praga 1968 y Obrození malých evropských národu. I: Národy severní a východní Evropy, Praga 1971.

${ }_{28}$ Aparte del citado «Vorkampfer» véase también: HROCH, M.: «Das Erwachen kleiner Nationen als Problem der komparativen sozialgeschichtlichen Forschung»: SCHIEDER, Theodor (Ed.): Sozialstruktur und Organisation europäischer Nationalbewegungen, Munich 1971, pp. 121-139.

${ }^{29}$ En el tomo Hroch, M.: Social Preconditions of National Revival in Europe: A Comparative Analysis of the Social Composition of Patriotic Groups among the Smaller European Nations Cambridge 1985.

${ }_{30}$ Él mismo ha afirmado recientemente que su opción metodológica era conscientemente innovadora. Véase HROCH, M.: «Real and constructed: the nature of the nation» en HALL, J. A.: The State of the Nation. Ernest Gellner and the Theory of Nationalism, Cambridge 1998, pp. 91-106, aquí p. 91.
} 
El proceso de construcción nacional lo veía Hroch ligado al surgimiento del capitalismo pero su análisis, lejos de resultar unilateral y economicista, resaltaba el papel de las elites y de los constructores de cultura en la creación de un espacio social y político nacional. Hroch apreciaba también - muy en la tradición de la historiografía centroeuropea ${ }^{31}$ - diferencias sustanciales entre los movimientos nacionales de Europa Centrooriental y Occidental. Él basaba estas diferencias en que en países como Inglaterra, Francia - e incluso Españala nación había surgido en el conflicto entre la burguesía y la nobleza, pero el Estado moderno había sido producido «bajo el dominio de una cultura étnica» ${ }^{32}$. En Europa Central y Oriental, sin embargo - y siempre según Hroch-, «una clase gobernante 'exógena' dominaba a grupos étnicos que ocupaban un territorio compacto pero que carecían de 'su propia' nobleza, unidad política o tradición literaria continua»33.

Basado en su análisis de las intelligentsias "patrióticas» proponía Hroch un modelo de desarrollo de la dinámica nacionalista, en el aspecto cultural, que ha llegado a convertirse en prototípico. En primer lugar Hroch definía una fase A, el período en que los intelectuales se preocupan por la nación en potencia, fijan ortografías y gramáticas, recopilan folklore, escriben historias. La fase siguiente, la $\mathrm{B}$, es el período de agitación patriótica, en el que se multiplican los partidos y asociaciones, se lleva por toda la nación la buena nueva del evangelio nacional. La fase $\mathrm{C}$ y última, es la del auge del movimiento nacionalista, cuando se convierte en un fenómeno de masas.

Los trabajos de Hroch se han revelado muy influyentes para la investigación posterior, aunque no podemos olvidar que, sin embargo, no hay demasiados estudios posteriores que sigan su ejemplo empírico.

También de un país de fuerte tradición nacionalista y por entonces igualmente situado al otro lado del telón de acero, Polonia, surgió un análisis que, menos influyente en el mundo anglosajón, sí lo fue en cambio en Centroeuropa. Nos referimos a los trabajos de Józef Chlebowczyk, quien en un libro magistral — cuya primera versión se publicó ya en $1975^{34}$ — hacía recapitulación

31 Véase el importante libro póstumo de SzÜCS, Jenö: Vázlat Európa bárom történeti régiójáról, Budapest 1983, (Edición alemana: Die Drei bistorischen Regionen Europas, Frankfurt/Main 1990) y para una crítica de la construcción del concepto de Europa Oriental, acusando a la Ilustración europea de la división de Europa, Wolff, Larry: Inventing Eastern Europe. The Map of Civilization on the Mind of Enlightenment, Stanford 1995.

32 Hroch, M.: «From National Movement to the Fully-Formed Nation: The Nation-Building Process in Europe» en New Left Review 198 (1993) 3-20. Citamos siguiendo la reedición en ELEY/SUNY (Eds): Becoming National..., pp. 60-77, aquí p. 61.

33 Íbid. p. 61.

34 CHLEBOwCZYK, Józef: Procesy narodotworcze w wschodniej Europie Srodkowie w dobie kapitalizmu (od schylku XVIII do poczatku XX, Varsovia 1975. Hay una edición inglesa que, aunque castrada de buena parte del aparato de notas, da una visión muy clara de los aportes teóricos del libro. Véase CHLEBOWCZYK, J.: On small and young nations in Europe. Nation-forming processes in ethnic borderlands in East-Central Europe, Breslau 1980. 
de visiones teóricas en torno al problema nacional, cotejándolas con un impresionante y riquísimo material histórico. Su visión del asunto estaba relacionada con los trabajos de Hroch - no en vano su autor era especialista en Checoslovaquia - y al mismo tiempo se manifestaba como una peculiar fusión de Karl Deutsch y del marxismo. Chlebowczyk abundaba en las diferencias entre nacionalismos del este y del oeste, aunque apuntando a una divergencia, más que nada, de origen económico: el retraso modernizador esteeuropeo era visto como una fase primera - también en lo nacional- dentro de un desarrollo, en cierta medida, necesario.

Todos estos trabajos que pusieron de manifiesto las bases de comprensión del nacionalismo como un fenómeno moderno, desvelando su origen en las transformaciones de la modernidad, se hallaban fuertemente enraizadas en una visión economicista del problema. Hacía falta dar un paso más allá, engarzando el aspecto duro (la construcción nacional) con la clara importancia, incluso preponderancia, del aspecto blando de la cuestión (la ideología y el sentimiento nacional). Este paso lo daría, a principios de los ochenta, Benedict Anderson con una sola obra, Imagined Communities, (que ganaría en importancia con su reedición ampliada a principios de los noventa) ${ }^{35}$. El título del libro acabaría por convertirse en una frase hecha, utilizada, deformada y malinterpretada por doquier.

Para Benedict Anderson el concepto de "nación» es en realidad una creación cultural de «comunidades imaginadas», de un tipo sólo posible con la expansión durante el siglo XVIII de una nueva mentalidad. Si acudimos a su definición, ya clásica, del término «nación», nos enteramos de que ésta es «una comunidad política imaginada, e imaginada como inherentemente limitada y soberana» ${ }^{36}$.

Según Anderson, lo que hizo imaginables las nuevas comunidades, es decir, representables y actuables a un tiempo, fue una «casi fortuita pero explosiva interacción entre un sistema de producción y relaciones productivas - capitalismo-, una tecnología de comunicación -imprenta- y la fatalidad de la diversidad linguística humana» ${ }^{37}$. Formulaciones que, en realidad, no son tan nuevas, pero que nunca habían sido expresadas con tan rotunda claridad y concisión, y que permiten conciliar las explicaciones mentalistas y basadas en la aparición de sentimientos nacionales con aquellas otras que entienden que el nacionalismo surge a partir de respuestas sociales a los cambios económicos. Y esto es así porque se hace hincapié en que el nacionalismo, de donde quiera que lo hagamos surgir, es ante todo un fenómeno de mentalidad, es decir, en última instancia, de cultura, no de patología psicológica o histórica, y que tampoco se trata simplemente de un hábil plan de una clase social para mantener su dominio económico.

35 ANDERson, Benedict: Imagined Communities. Reflections on the Origin and Spread of Nationalism, Londres 1991, Ed. Revisada (la edición original es de 1983).

${ }^{36}$ ANDERSON, Imagined Communities... p. 6.

37 ANDERSON, Imagined Communities... pp. 42-43.

Hispania, LXI/3, núm. 209 (2001) 933-964 
El cambio de mentalidad que Anderson describe se apoya fundamentalmente en la transformación del concepto de tiempo histórico en el mundo posterior a la desintegración de las monarquías tradicionales, y en el comienzo de la destrucción de la sociedad y la economía campesinas tradicionales, con el consiguiente desarrollo del industrialismo y la economía capitalista. Esto, que trajo consigo la laicización de la sociedad y el cada vez mayor recurso a la ciencia, entendida como conocimiento socialmente aceptado, para cumplir funciones sustitutivas de la religión, parece mostrarnos al nacionalismo como un producto de la primera más que de esta última (como otros autores opinan en cambio) ${ }^{38}$. El nacionalismo sería, en todo caso, una "religión científica» o una "ciencia religiosa» o, al menos en sus inicios, cumpliría esta función. No resultarían ajenos a ello la institucionalización y el desarrollo de las ciencias sociales: historia, sociología, geografía, etnología, economía...

Una matización de estos planteamientos desde un punto de vista de historia de las ideas la ha llevado a cabo Liah Greenfeld ${ }^{39}$. Greenfeld, con evidente buen tino, ha salido al paso de las concepciones del nacionalismo como producto de un lenguaje común, o de tradiciones estatales compartidas, de una unidad racial o, incluso, de una historia propia. En su opinión «el nacionalismo no tiene por qué ir ligado a ninguno de esos factores, aunque por lo general vaya ligado al menos a uno de esos factores». Lo cual quiere decir que «el nacionalismo no es necesariamente una forma de particularismo». La definición de Greenfeld es que se trata de una «ideología política (o un tipo de ideologías políticas que derivan del mismo principio básico), y como tal, no tiene por qué ser identificada con ninguna comunidad en particular» ${ }^{40}$. La forma en que ha llegado a esta definición, a través de una análisis de la evolución histórica del término «nation», nos muestra otro de los principales factores del nacionalismo: su referencia al «Pueblo Soberano» y permite explicar tanto los nacionalismos de Estado como los que no lo son.

Porque, según Greenfeld, el concepto ha ido evolucionando desde señalar a un grupo de extranjeros provenientes de una misma zona geográfica, hasta designar a una élite - en las universidades medievales y los concilios de la iglesiay venir luego a identificarse con el pueblo soberano, una identidad cuya primera aparición cifra Greenfeld en la Inglaterra del siglo XVI. La última transformación fue la de que esa soberanía popular — ahora nacional- se refería a un «único y concreto» pueblo. La ligazón de esta concepción con la de «democracia» —en el sentido liberal del término- es evidente: la soberanía pertenece al pueblo y

${ }^{38}$ Una perspectiva de las relaciones entre nacionalismo y religión, algo antigua pero aún valiosa en BARON, Salo W.: Modern Nationalism and Religion, Nueva York 1960.

39 Greenfeld, Liah: Nationalism. Five Roads to Modernity, Cambridge, Londres 1993. Véase también una diferenciación entre los tipos de nacionalismo europeos «orientales» y «occidentales» en GreENFELD, L., «Nationalism in Western and Eastern Europe Compared» en HaNSON, Stephen E. / SPOHN, Wilfried (Eds.): Can Europe Work? Germany and the Reconstruction of Postcommunist Societies Seattle/Londres 1995, pp. 15-23.

40 Todas la citas en: Greenfeld, Nationalism. Five..., p. 7

Hispania, LXI/3, núm. 209 (2001) 933-964 
todos los estratos de éste son iguales entre sí. La democracia utópicamente «liberal», pues, surgió con la necesidad de expresarse nacionalmente y el propio nacionalismo se expresó desde un principio como democratismo y como liberalismo, aunque a la luz de acontecimientos posteriores tal caracterización nos vaya resultando ya extraña.

La ideología política que Greenfeld describe como expandiéndose a través del mundo durante el siglo XIX tiene como caso primigenio y, a la vez, modelo, a Inglaterra — de modo parecido a Hastings, a quien comentaremos luego-y como realización más perfecta a Estados Unidos, lo cual es solamente lógica consecuencia de su idea de la relación entre democracia y nacionalismo. Para Greenfeld, el mundo moderno es un resultado del surgimiento de las naciones y de la ideología nacional, pues estas permitieron el desarrollo de democracias liberales que pudieron dedicarse a prosperar.

Otros aportes a esta «nueva ola» han sido quizá de menor envergadura teórica y, sin embargo, tan decisivos como los mencionados para la extensión de esta visión del nacionalismo. Un ejemplo importante sería John Breuilly ${ }^{41}$ quien, de forma parecida a Wallerstein ${ }^{42}$, concede la mayor importancia al papel del Estado y al moderno sistema internacional a la hora de crear el nacionalismo. Otro sería Rogers Brubaker ${ }^{43}$ con sus trabajos de índole funcionalista y con su análisis de la diferencia entre el modelo nacional francés y el alemán - derecho de suelo, derecho de sangre- una diferencia que él encuentra fundamental a la hora de analizar el nacionalismo en Europa.

Entre estas obras, las más polémicas y, yo diría, más leídas, han sido las de Eric Hobsbawm. Las capacidades narrativas y pedagógicas de Hobsbawm le han servido para realizar una síntesis de la concepción que del nacionalismo tenía el movimiento comunista de la época del frente popular con las innovaciones en torno a la construcción cultural y social del nacionalismo. Su visión, fuertemente crítica del asunto, ha servido para expresar un rechazo al nacionalismo (re)surgido de las crisis de finales de los ochenta y primeros noventa y compartido por una parte de la izquierda y el conservadurismo europeos - de la misma forma que otra parte de la izquierda y del derechismo se han aliado en su lucha contra la pérdida del Estado Nacional y el proceso globalizador-. El hecho de que los influyentes trabajos de Hobsbawm se presenten como una alternativa ideológica no es obstáculo para que, sin embargo, resulten académicamente excelentes. Ya en los años ochenta, en su conocida antología $a^{44}$ coeditada con Ranger, desafiaba la base ideológica de todo nacionalismo - la conexión con el pasado- mostrando que casi cada sacrosanta tradición no es sino un invento reciente. Con posteriori-

\footnotetext{
41 BREUILLY, John: Nationalism and the State, Manchester 1982.

42 Por ejemplo en Wallerstein, Immanuel: The Politics of the World-economy, Cambridge 1984.

${ }_{43}$ BRUBAKER, Rogers: Citizenship and Nationbood in France and Germany Cambridge 1992 y Nationalism Reframed. Nationbood and the National Question in the New Europe, Cambridge 1996.

${ }_{44}$ HobSBAwm, Eric J. /RANGer, Terence O. (Eds.): The Invention of Tradition, Cambridge 1983.
} 
dad, su libro Nations and Nationalism since $1780^{45}$ se convirtió en la bestia negra de muchos patriotas, en especial en el este de Europa. Acusado de «prejuicios antinacionalistas» (entre otros por Mirovslav Hroch), su obra halló con rapidez un lugar en la literatura científica y ha conocido traducciones y ediciones por doquier.

No se trata sin embargo de una obra original en exceso. A la conciencia de que la nación es una creación reciente, cuyas características estaban más allá del horizonte de comprensión de las poblaciones del pasado se une una visión instrumental de la ideología nacional por parte de concretos grupos sociales (la burguesía), aunque sin olvidar los peligros del colectivismo nacionalista de base popular. Así, el fenómeno nacional es construído desde arriba pero siempre contando con los sentimientos y las necesidades de la gente de a pie. Para Hobsbawm - como para el resto de los investigadores enmarcados en el consenso- «el nacionalismo viene antes que las naciones» ${ }^{46}$, lo que implica la existencia histórica de un trabajo ideológico y social que no se limita a organizar un movimiento nacionalista sino que construye la propia nación a liberar.

Todos estos trabajos han acabado por conformar un contexto de investigación que, incluso teniendo en cuenta las diferencias y contradicciones entre ellos, puede definirse como un paradigma, casi en sentido kuhniano. Apoyándose en estos hallazgos ha ido apareciendo una cada vez más compleja historiografía sobre nacionalismo que podríamos ejemplificar con dos publicaciones que son, a nuestro juicio, modélicas: por un lado, la colección editada por Eva SchmidtHartmann ${ }^{47}$ y por otro, el libro de Tomasz Kizwalter sobre el proceso de construcción nacional polaco ${ }^{48}$.

Una circunstancia historiográfica ha venido a reforzar el efecto de estos estudios. Se trata del surgimiento a lo largo de las últimas décadas, de una historia posmoderna, que, aunque muy diversificada y a veces desde presupuestos muy alejados de Gellner o Hobsbawm, ha incidido sin embargo en la reconsideración y en la negación de todo "esencialismo" y de todo "pensamiento fuerte», debilitando por ello las posibles objecciones al nuevo paradigma. Vamos ahora a repasar algunas de estas tendencias.

\section{SEGUNDO NIVEL: COMPLEJIDADES POSMODERNAS}

Afirma Keith Jenkins ${ }^{49}$ — siguiendo a Lyotard — que la posmodernidad es una condición general socio-económica y política, una época dentro de la que

\footnotetext{
45 HobSBAwM, E.: Nations and Nationalism since 1780: Programme, Myth, Reality, Cambridge 1990.

${ }^{46}$ HOBSBAWM, Nations and Nationalism...., p. 10

47 SCHMIDT-HARTMANN, Eva (Ed.): Formen des nationales Bewußtseins im Lichte zeitgenössischer Nationalismustheorien, Munich 1994.

48 KIzwalter, Tomasz: O nowoczesnosci narodu. Przypadek Polski, Varsovia 1999.

49 Por ejemplo en Jenkins, Keith: On «What is History?»: From Carr and Elton to Rorty and White, Londres 1995.
}

Hispania, LXI/3, núm. 209 (2001) 933-964 
nos encontramos, y no una moda o ideología que podamos aceptar o descartar a voluntad. Si ello fuera cierto, cualquier escrito actual, cualquier pedazo de papel manchado, resultaría posmoderno. Teniendo esto en cuenta, el uso de la palabra posmoderno que vamos a hacer aquí no se limita a las producciones intelectuales diseñadas en parámetros derridianos o foucaultianos. Independientemente del valor de estas aportaciones concretas, la renovación de temas y aproximaciones de las dos últimas décadas dentro de la historiografía ha sido tan abismal que muy bien podemos hablar de complejidad posmoderna ${ }^{50}$. La atención al individuo y a lo concreto, por encima de las generalidades de la historia social ha conducido a una antropología histórica ${ }^{51}$ que, en sus diversas versiones (anglosajona ${ }^{52}$, francesa o alemana) ha intentado abrir nuevos espacios de investigación hasta ahora vírgenes. La crítica de textos, el «giro linguístico», y la influencia de la semiótica - tanto francesa como soviética- han dado nuevo valor al análisis tanto de las propias producciones escritas como de casi cada objeto, paisaje o artefacto, considerados ahora como textos a ser leídos y desentrañados por sí mismos.

A ello hay que añadir el aporte de los "Cultural Studies» 53 que, comenzando en los años cincuenta con los trabajos de ciertos marxistas ingleses - Richard Hoggart y Raymond Williams, aunque no hay que menospreciar la influencia de E.P. Thompson - se propusieron integrar la cultura en los análisis históricos marxistas, hasta entonces de tono casi exclusivamente político o económico. Si bien hoy día, sobre todo en EE.UU., los «estudios culturales» amenazan con ahogar la historiografía en un mar de escritos excesivamente particularistas, es cierto que resulta ya imposible pensar en una historia que no tenga en cuenta que absolutamente todo fenómeno humano está empotrado en cultura. La aten-

${ }^{50}$ Como guía para el presente laberinto historiográfico citaré tan sólo el denso y extremadamente plural libro de HerNANDEZ SANDOICA, Elena: Los caminos de la Historia. Madrid 1995, la no menos densa propuesta de VRIES, Piers: Verbaal en betoog. Geschiedbeoefening tussen postmoderne vertelling en sociaal-wetenschappelijke analyse, Leiden 1995, y la compilación un tanto partidaria —por culturalista- pero excelente de BONNELL, Victoria E. / HuNT, Lynn (Eds.): Beyond the cultural turn, Berkeley 1999. Una penetrante visión de la teoría de la disciplina, tras el hundimiento del paradigma marxista y la revolucion posmoderna, en el penúltimo libro del recientemente fallecido TOPOLSKY, Jerzy: Swiat bez bistorii, Poznan 1998.

51 Sobre el tema, aunque excesivamente centrado en la versión alemana del asunto: DüLMEN, Richard van: Historische Anthropologie. Entwicklung, Probleme, Aufgaben, Colonia, Weimar, Viena 2000. Dülmen, uno de los fundadores de la revista «Historische Anthropologie», es partidario de una opción europea que, mezclando tradiciones de historia cultural alemana con los hallazgos de la escuela de Annales, difiere en cierta medida de las producciones americanas.

52 La referencia fundamental aquí es Clifford Geertz, aunque hay que decir que todas las nuevas perspectivas antropológicas — no sólo anglosajonas- le deben mucho. Véase, por ejemplo su The Interpretation of Cultures, Nueva York 1973.

53 Para comprender el origen de esta perspectiva puede verse DwORKIN, Dennis, Cultural Marxism in Postwar Britain. History, the New Left and the Origins of Cultural Studies Durham/Londres 1997.

Hispania, LXI/3, núm. 209 (2001) 933-964 
ción a la cultura popular y a las producciones culturales masivas resulta en extremo importante a la hora de analizar un fenómeno como el nacionalismo que es, sobre todo, un fenómeno de masas.

Todo ello no es, en realidad, posmodernismo puro y duro, sino más bien, desarrollos de otras tradiciones que han sido, sin embargo, influidos por las filosofías del «pensamiento débil». En buena medida, la aportación principal de la posmodernidad —en su sentido restringido- y la única que, a mi juicio, tiene todas las oportunidades de perdurar, es la atención a los elementos metahistóricos, es decir a las fronteras del lenguaje del propio investigador, la comprensión de las limitaciones de la perspectiva propia, y con ello la desconfranza ante las «verdades» supremas.

Todos estos fenómenos han servido para apuntalar y a la vez transgredir, el paradigma modernista de estudio del nacionalismo. Han surgido así trabajos muy diversos y plurales que arremeten con el tema desde puntos de vista muy complejos pero conservando una característica común: la conciencia del nacionalismo como un artefacto cultural y de la nación y de la identidad de ella derivada como una ambigua y lábil construcción.

La identidad es uno de los principales temas entre los que podemos agrupar las últimas investigaciones. Si seguimos a Anthony Giddens, las «transformaciones de la auto-identidad y la globalización, (...) son los dos polos de la dialéctica de lo local y lo global en las condiciones de la modernidad tardía ${ }^{54}$. Aunque sería demasiado exagerado tachar a Giddens de posmoderno -en el sentido francés-, está claro que su influencia intelectual ha sido poderosa en los años noventa. Su intento de crítica del marxismo desde un punto de vista pos-industrial es básico a la hora de comprender los nuevos aportes sobre nacionalismo. Un punto fundamental de su crítica a Marx es que

«considerar a las sociedades modernas como la culminación de un proceso de expansión progresiva de las fuerzas de producción impide percibir cuán diferentes son estas sociedades de toda forma de orden tradicional. Las 'sociedades' modernas son estados-nación existiendo en el interior de un sistema de estados-nacionales» $\$ 5$.

El nacionalismo es por tanto un problema de la modernidad y puede ser descrito como una forma moderna de construir la identidad individual. Para Giddens la identidad es un problema de los tiempos modernos, o mejor dicho, sólo en los tiempos modernos se llega a ver la identidad como un problema. No debiera buscarse la identidad «en el comportamiento [de la persona] ni - por importante que esto sea- en las reacciones de otros, sino en la capacidad de mantener

\footnotetext{
${ }^{54}$ GIDDENS, Anthony: Modernity and Self-Identity. Self and Society in the Late Modern Age, Cambridge 1991, p.32.

ss GIDDENS, A.: The Nation-State and Violence. Vol. Two of a Contemporary Critique of Historical Materialism, Berkeley 1987, p. 1.
} 
una narrativa particular en funcionamiento» ${ }^{56}$. Por tanto, la creación de una identidad individual deviene producción de una narración que sea coherente, o al menos funcione como si lo fuera:

«los cambios en los aspectos íntimos de la vida personal (...) están directamente ligados al establecimiento de conexiones sociales de muy amplio alcance (...) el nivel del distanciamiento espacio-temporal introducido por la alta modernidad es tan extenso que, por primera vez en la historia humana el «yo» y la «sociedad» están interrelacionados en un ambiente global» 57 .

Siguiendo estos razonamientos, la identidad ${ }^{58}$ ha acabado por convertirse en uno de los principales subgéneros del estudio del nacionalismo, y no sólo de él59. La construcción cultural de una conciencia nacional parece haberse convertido en el tronco principal de los trabajos actuales del nacionalismo, perjudicando análisis de tipo políticosocial (movimientos nacionalistas, programas, actividades...).

El sociólogo Bernhard Giesen ha intentado encontrar una teoría general de la construcción de identidad colectiva, fundamentándola empíricamente con el estudio del caso alemán ${ }^{60}$. Curiosamente su tesis remite a las de Elie Kedourie o Hans Kohn, en el sentido de que la mayor importancia a la hora de construir el nacionalismo la reciben los intelectuales quienes, en el siglo XIX, conceden al discurso sobre identidad nacional «el rango de referencia última» ${ }^{61}$. El análisis de este proceso lo acomete Giesen mediante una evolución de «códigos» desarrollados por los intelectuales a lo largo del tiempo hasta el momento en que la nación, desde una idea contrapuesta al viejo orden deviene una prosaica realidad cotidiana. Únicamente quedaría por explicar en qué modo las creacio-

56 GIDDENS, Modernity and Self-Identity... p. 54

57 GIDDENS, Modernity and Self-Identity... p. 32

${ }^{58}$ Un jarro de agua fría arrojan Mikuláš Teich y Roy Porter en «Introducción» en TEICH, Mikuláš / PORTER, Roy (Eds.): The National Question in Europe in Historical Context, Cambridge 1993, pp. XIV-XX: «resulta inadecuado hacer de la identidad nacional el alfa y el omega de la cuestión nacional» (cit. p.XIX). El propio Teich - de origen eslovaco- se ha mostrado repetidas veces muy crítico de las teorías actuales sobre nacionalismos, por ejemplo durante el XII Congreso Mundial de Historia Económica en Madrid, en agosto de 1998.

59 Una visión del tema desde el culturalismo de la escuela de Birmingham: HaLl, Stuart / GAY, Paul du (Eds.): Questions of Cultural Identity, Londres 1996.

${ }^{60}$ GIESEN, Bernhard, Die Intellektuellen und die deutsche Nation. Eine deutsche Acbsenzeit, Francfort/Main 1993. Véase también el resultado de un proyecto financiado por el Estado de Hessen y dirigido por Giesen que ha aportado uno de las más interesantes colecciones de análisis del nacionalismo - no sólo alemán, hay aportaciones incluso sobre el nacionalismo españolista- de la última decada: GIESEN, B. (ed.) Nationale und kulturelle Identität. Studien zur Entwicklung des kollektiven Bewußtseins in der Neuzeit, Francfort/Main 1991. Véase también BERDING, Helmut (Ed.) Nationales Bewußtsein und kollektive Identität. Studien zur Entwicklung des kollektiven Bewußtseins in der Neuzeit 2, Francfort/Main 1994.

61 GIESEN, Die Intellektuellen und..., p. 85.

Hispania, LXI/3, núm. 209 (2001) 933-964 
nes de los intelectuales se difunden entre el resto de la población y por qué razón son acogidas y asumidas.

Giesen menciona - de manera, a nuestro parecer insuficiente - la «trivialización cotidiana» de las ideas de los intelectuales como el «mecanismo» (?) de transporte de dicho pensamiento hacia abajo, hacia el resto de la sociedad. De modo mucho más convincente ha mostrado este mecanismo el libro de Michael Billig $^{62}$, quien, basándose sobre todo en la sociedad norteamericana contemporánea, ha mostrado en qué forma la identidad se sostiene a base del «nacionalismo banal», de los colores nacionales en bolsas de plástico, de los mapas del tiempo, de la melodía del telediario. En este sentido, otra publicación de interés es la de Lauren Berlant, quien enlaza con las corrientes contemporáneas de uso de la literatura y de estudios literarios ${ }^{63}$.

El estudio de la identidad nacional se ha desarrollado también a base de grandes proyectos, realizados por un grupo de autores, que, repasando mitos y autoimágenes, han ofrecido descripciones del «corpus nacional». Estos proyectos si bien no específicamente posmodernos - más bien académicos, diría yosólo se explican por la ya aludida preponderancia de la identidad en una sociedad posindustrial. Como ejemplo más importante podemos citar los de Pierre de Nora ${ }^{64}$ y Ralph Samuel ${ }^{65}$ - aunque en el caso francés el resultado produce la sensación de ser más una celebración de la propia identidad, que un análisis crítico de ella.

Sin embargo, el núcleo de la investigación sobre identidad nacional proviene de las universidades norteamericanas donde se ha examinado una multitud de temas. Producido por la difusión del posmodernismo en el milieu académico y con el acicate de la creciente conciencia de las minorías étnicas, el estudio de la identidad - no sólo nacional - se ha convertido en objeto favorito de trabajo intelectual. Hacer un resumen de la miríada de publicaciones sería —en este lugar- empresa inabarcable, por lo que nos contentaremos con referirnos a alguno de los trabajos que más relevantes nos parecen.

Comenzaremos mencionando las obras de Katherine Verdery sobre Rumanía que son un modélico ejemplo de la perspectiva antropológica ${ }^{66}$. Por su parte, el texto de Linda Colley sobre la formación de la identidad de la «nación

\footnotetext{
62 BILLIG, Michael: Banal Nationalism Londres 1997.

63 BERLANT, Lauren, The Anatomy of National Fantasy: Hawthorne, Utopia and Everyday Life, Chicago 1991.

${ }^{64}$ NorA, Pierre de (Ed.): Les Lieux de Mémoire. I. La République, París 1984, II. La Nation, 3. Vols, París 1986, III. Les France, 3 Vols., Paris 1992.

65 SAMUEL, Ralph (Ed.): Patriotism: The Making and Unmaking of British National Identity III Vols. Londres, Nueva York 1989.

66 VERDERY, Katherine: Transylvanian Villagers: Three Centuries of Political, Economic and Ethnic. Change, Berkeley, Los Ángeles 1983; ibid. National Ideology under Socialism: Identity and Cultural Politics in Ceausescu's Romania, Berkeley, Los Ángeles 1991 y la antología editada junto con BANAC, Ivo / VERDERY, K. (Eds.): National Character and National Ideology in Interwar Eastern Europe New Haven 1995.
} 
británica» amenaza con convertirse en un clásico ${ }^{67}$. En la conformación de las identidades nacionales la escuela parece haber sido uno de los vehículos principales. Desde la obra pionera de Eugen Weber ${ }^{68}$ han surgido algunos estudios muy pormenorizados de algunos de estos procesos ${ }^{69}$. Un buen análisis del poder constructor de identidad que tiene los símbolos es el de Jan Kubik ${ }^{70}$, mientras que un conjunto muy plural de artículos, desde un punto de vista comparativo, centrado en la metáfora — y la realidad — de la «emoción» es el presentado en Nation und Emotion ${ }^{71}$. El uso de los materiales más aparentemente peregrinos y de la cultura (pop)ular, algo que se ha convertido habitual en los «cultural studies», queda ejemplificado en el estudio de Hebdige sobre la música caribeña ${ }^{72}$. Aunque en el presente artículo hemos querido reducirnos a libros, no podemos menos que citar un artículo que, aparte de los convincentes resultados científicos en él presentados, nos parece la quintaesencia de lo mejor que la perspectiva posmoderna puede aportar. Nos referimos al - ya muy conocido - trabajo de Yuri Szlezkine ${ }^{73}$, «La URSS como un apartamento comunal», en el que a través de una metáfora —esa "komunalka» ${ }^{74}$, las viviendas compartidas típicas de los países socialistas- se nos presenta toda una visión histórica de la construcción de las nacionalidades soviéticas.

Otro de los complejos de temas tratados más a menudo es el cuerpo. Historias del cuerpo, el cuerpo como soporte de la acción del poder, la autodefinición del propio cuerpo, la sexualidad, creada y recreada... Todo ello, con su inicio en la obra de Michel Foucault y, por qué no, de Kantorowicz ${ }^{75}$, se ha convertido

67 COLLEY, Linda: Britons: Forging the Nation 1707-1837, New Haven 1992.

68 WeBer, Eugen: Peasants into Frenchmen. The Modernization of Rural France 1870-1914, Standford 1973.

69 Para Francia, Citron, Suzanne: Le mythe national. L'bistoire de la France en question, Paris 1989; para Italia SOLDANI, Simonetta (Ed.) Fare gli Italiani. Scuola e cultura nell'Italia contemporanea, Bolonia 1993; para Alemania BECKER, Helmut / KLUCHERT, Gerhard: Bildung der Nation. Schule, Gesellschaft und Politik vom Kaiserreich zur Weimarer Republik, Stuttgart 1993.

70 KUBIK, Jan: The Power of Symbols against the Symbols of Power. The Rise of Solidarity and the Fall of State Socialism in Poland, Pennsilvania 1994. Puede enlazarse también con el análisis comparativo de MACH, Zdislaw: Symbols, Conflict and Identity. Essay in Political Antbropology, Nueva York 1993, que presenta una serie de casos de construcción y contraconstrucción de identidad nacional en perspectiva, pese al título, más histórica que política.

71 FranCOIS, Etienne / SIEGRIST, Hannes / VOGEL, Jakob (Eds.): Nation und Emotion, Göttingen 1995 .

72 HebDige, Dick: Cut'n'Mix: Culture, Identity and Caribbean Music, Londres 1987.

73 SZLÈZKINE, Yuri: "The USSR as a Communal Apartment, or How a Socialist State Promoted Ethnic Particularism» en: Slavic Review 53 2/1994. Una reedición en ELEY/SUNY: Becoming National....

74 Sobre la «Komunalka» puede verse SCHLÖGEL, Karl: «Kommunalka o el comunismo como una forma de vida. Hacia una topografía histórica de la Unión Soviética» en Cuadernos de Historia Contemporánea, Madrid, 22 (2000): 257-273.

75 Un antecedente que se olvida a menudo, véase si no: KaNTOROWICZ, Ernst: The King's Two Bodies. A Study in Medieval Political Theology, Princeton 1957.

Hispania, LXI/3, núm. 209 (2001) 933-964 
hoy día en una especie de moda intelectual. Que no se trata de algo nuevo, sin embargo, lo demuestra la importancia que el deporte y la actividad física han tenido-siempre para los constructores de naciones - más allá de la pura simbología o representación del cuerpo de la nación, de la nación como organismo-.

El cuerpo como una forma de la memoria ha recibido, pues, atención ${ }^{76}$ pero también la (in)corporación de la nación, su escenificación - el primero de mayo $^{77}$, los desfiles militares, las demostraciones gimnásticas- ${ }^{78} \mathrm{o}$ el papel nacional de las organizaciones deportivas ${ }^{79}$. La raza - en el sentido norteamericano del término ${ }^{80}$ - ha irrumpido con fuerza en los estudios del cuerpo y del nacionalismo, mostrandose como, una vez más, una construcción con raíces sociales, económicas o de distribución de poder ${ }^{81}$.

El estudio de los problemas relacionados con el género ocupa una parte sustancial de las nuevas publicaciones. No cabe duda alguna de que una de las principales transformaciones de la historiografía de la segunda mitad del siglo XX ha sido el nacimiento de una historiografía «feminista» al lado de una preocupación cada vez mayor por el papel de la mujer en la historia humana. Esto ha influído, por supuesto, en los estudios del nacionalismo. Curiosamente, es la Alemania nazi ${ }^{82}$ - y en cierta medida también la época del «Reichsgründung»,

76 Connerton, Paul: How Societies Remember, Cambridge 1989.

77 Un reciente estudio que entra de lleno en todas las convenciones del genero posmoderno, pero armado con una sólida documentación: SOwINSKI, Paweł: Komunistyczne swieto. Obchody 1 maja w latach 1948-1954, Varsovia 2000.

78 Véase, por ejemplo: VORSTEHER, Dieter (Hrsg.) (1996) Parteiauftrag: Ein neues Deutschland. Bilder, Rituale und Symbole der früben DDR Berlin.

79 Sirvan como máximo ejemplo —y mejor estudiado - las Turnverein, las organizaciones gimnásticas alemanas que, de origen nacionalista, fueron luego adoptadas también por el movimiento obrero para recibir más tarde, en la $\mathrm{RDA}$, un sentido nacional(ista) nuevo. Véase, en un modo historiográfico tradicional, DüDING, Dieter: Organisierter gesellschaftlicher Nationalismus in Deutschland (1808-1847). Bedeutung und Funktion der Turner- und Sängervereine für die deutsche Nationalbewegung, Munich 1984. Para Francia existe otro clásico HolT, Richard: Sport and Society in Modern France, Londres 1981 y bastantes nuevas aportaciones como HUBSCHER, Ronald (Ed.): L'bistoire en mouvements. Le sport dans la société française (XIXe-XXe siècle), París 1992. De Richard Holt hay también una historia — bastante académica- del deporte británico: Sport and the British : a modern bistory, Oxford 1989. Una obra colectiva excelente sobre la organización deportiva Sokol, de origen checo y extendida luego a otros movimientos nacionalistas eslavos, es BLECKING, Diethelm. (Ed.): Die slawische Sokolbewegung. Beiträge zur Geschichte von Sport und Nationalismus in Osteuropa, Dortmund 1991.

${ }^{80}$ Una introducción en BACK, Les (Ed.) Theories of Race and Racism: a Reader, Londres 2000.

81 Una brillante aportación, relacionada con el Centre for Contemporary Cultural Studies de la Universidad de Birmingham - la cuna de los estudios culturales británicos-GilroY, Paul: 'There Ain't No Black in the Union Jack': The Cultural Politics of Race and Nation, Londres 1987. Desde una perspectiva de "género» puede verse ANTHIAS, Floya / YUVAL-DAVIS, Nira: Racialized Boundaries: Race, Nation, Gender, Colour and Class and the Anti-racist Struggle, Londres/Nueva York 1991.

82 Véase por ejemplo Bridenthal, Renate / Grossman, Atina / KaPlan, Marion (Eds.) When Biology Became Destiny: Women in Weimar and Nazi Germany, Nueva York 1984 y KoONZ, Claudia: Mother in the Fatherland: Women, the Family, and Nazi Politics, Nueva York 1986. 
el último tercio del s. XIX - la que parece haber dado más fruto a la hora de estudiar esta interrelación. Si ya en las obras de George L. Mosse ${ }^{83}$ encontramos el tema, podemos hacer además referencia a otros estudios, como la reflexión de Blackbourn acerca de las relaciones entre nación, género y catolicis$\mathrm{mo}^{84}$, la revolución de 1848 contemplada desde el punto de vista de la mujer ${ }^{85}$ o la política de género y sus relaciones con el Estado del bienestar ${ }^{86}$.

Una de las ideas claves de la interpretación más feminista ${ }^{87}$ ha sido que el nacionalismo y la nación pueden servir como formas de perpetuar las diferencias - entre ellas las de género-. Un segundo núcleo de estudios giraría en torno a la ambigüa participación de la mujer en los movimientos nacionalistas -activamente o como mero símbolo pasivo. Se pueden ver también aportaciones importantes, de temple muy variado, en la importante y clarificadora antología de Nira Yuval-Davis y Floya Anthias ${ }^{88}$, en el reciente análisis comparativo de Susan Gal ${ }^{89}$, o en los artículos de las revistas Feminist Review (especialmente el número 44 de 1993, dedicado a Nationalism and National Identities) y Gender E History (esp. el número 5/2 de 1993, dedicado a Gender, Nationalism and National Identities).

La topografía de la nación, el análisis de los paisajes nacionales es otro de los subgéneros que más productivos se han mostrado. El hecho de la investigación de mitos, artes, monumentos y arquitecturas relacionadas con la nación y el nacionalismo no es fenómeno nuevo. En cierta medida, y muchas veces de un modo marginal, han formado parte de las preocupaciones de historiadores del pasado. Sin embargo sólo en los últimos tiempos se ha acometido de manera más o menos sistemática el análisis de este aspecto de la realidad.

Como ejemplo de una revisión de artefactos e imágenes empotradas en distintas formas de arte me gustaría señalar la exposición del Deutsches Historisches Museum «Mythen der Nationen» («Mitos de las Naciones») que tuvo lugar en 1998. La exposición —y el catálog $0^{90}$ de ella, que contiene una importante serie de ensayos, incluyendo análisis de países no presentes en la exposición- mostraba a través de pintura (la pintura historicista del XIX, sobre todo), esculturas, grabados y objetos de todo tipo (desde abanicos a monedas)

\footnotetext{
${ }^{83}$ MOSSE, George L.: Nationalism and Sexuality: Middle-Class Morality and Sexual Norms in Modern Europe, Madison 1985.

${ }^{84}$ BlackBourn, David: Marpingen. Apparitions of the Virgin Mary in Nineteenth-Century Germany, Nueva York 1994.

${ }^{85}$ LIPP, Carola (Ed.): Schimpfende Weiber und patriotische Jungfrauen. Frauen in Vormärz und in der Revolution 1848/49, Bühl-Moos 1986.

${ }^{86}$ BoCK, Gisela / Thane, Pat (Eds.): Maternity and Gender Policies: Women and the Rise of the European Welfare States, 1880-1950s, Londres 1991.

87 Véase por ejemplo MC CLINTOCK, Anne: Imperial Leather: Race, Gender, and Sexuality in the Colonial Contest, Londres 1994.

88 ANTHIAS, Floya / YUVAL-Davis, Nira (Eds.): Women-Nation-State, Londres 1989.

89 GAL, Susan: The Politics of Gender after Socialism: a Comparative-Historical Essay, Princeton 2000.

90 FLACKE, Monika: Mythen der Nationen. Ein europäisches Panorama, Munich, Berlín 1998.
} 
las similitudes de la creación y propagación de imágenes nacionales a lo largo de toda Europa. El hecho de que la fabricación de mitos y tradiciones haya sido tan similar para el conjunto de las naciones europeas (en el catálogo se suma también EE.UU.) sirve como corroboración del lazo común, no sólo de las culturas europeas, sino del propio origen del nacionalismo. Es por esta tesis por lo que la exposición ha recibido críticas de haber sido políticamente selectiva.

El estudio de la arquitectura ${ }^{91}$ y el urbanismo como método de construcción del paisaje nacional y de la propia autoimagen de la nación, forma parte de esa otra corriente denominada «visual culture». Si seguimos la tesis ya citada de Michael Billig de la extensión del nacionalismo a la vida cotidiana, cada característica arquitectónica y cada objeto, — su estandarización, su «privatización", su reconocimiento como propio- puede llegar a tener un sentido nacional o antinacional. La cultura visual, entonces, es un buen medio para poder aprehender esa creación de la imagen nacional. Aunque hay algunos estudios fundamentales (la escuela en torno a Lou Taylor y David Crowley ${ }^{92}$ ha producido algunos de ellos), queda aún bastante por hacer.

La última corriente de estudios que está recibiendo atención es el poscolonialism $0^{93}$ que, con su origen en la India — por más que muchas veces desarrollado en universidades occidentales - se ha extendido con fuerza por Gran Bretaña, Australia y Estados Unidos. En general el poscolonialismo parece una reacción a la tesis de que todos los cambios del mundo moderno proceden de «Occidente», en especial de los países colonizadores europeos. Los poscolonialistas se rebelan contra la asunción de que las naciones asiáticas, americanas o africanas independientes ${ }^{94}$ sean meras copias —a veces malas copias- del modelo pri-

91 Por ejemplo en ÅmAN, Anders.: Architecture and Ideology in Eastern Europe During the Stalin Era Nueva York 1992, Dolgner, D.: Historismus. Deutsche Baukunst 1815-1900, Leipzig 1993; KIRITSCHENKo, J.: Zwischen Byzanz und Moskau. Der Nationalstil in der russischen Kunst, Munich 1991.

92 Por ejemplo, CROWLEY, David: National Style and Nation-State. Design in Poland from the Vernacular Revival to the International Style, Manchester 1992; TAYLOR, Lou: «The Search for a Polish National Identity -1945-68: An Analysis of the Textile Design Work of Professor Wanda Telakowska» en Stern-Gillet, Suzanne / Slawek, Tadeusz / Rachwal, Tadeusz / Whitehouse, Roger (Eds.) Culture and Identity. Selected Aspects and Approaches. Katowice 1996, pp. 396-414. Desde otro punto de vista, véase GoRDON-BOwe, N. (Ed.): Art and the National Dream, Dublin 1993. Una buena recopilación que abarca muy distintos trabajos -incluyendo uno sobre el franquismo-es Konstantynow, Dariusz / PAsieczNi, Robert / PASZKIEwiCZ, Piotr (Ed.) Nacjonalism $w$ sztuce $i$ bistorii sztuki 1789-1950, Varsovia 1998. Una muestra de lo que se comenzó a hacer en Rusia a partir del fin del dogmatismo: NekLiUdova, Militza G.: Traditsia i novatorsvo v russkom isskustvie Moscú 1991.

93 Un par de buenas introducciones al tema en AsHCroft, Bill / Griffiths, Gareth / TifFIN, Helen (Eds.), The Post-Colonial Studies Reader Londres 1995 y en MONGIA, Padmini (Ed.) Contemporary Postcolonial Theory Londres 1996.

${ }^{44}$ Algunos textos sobre nacionalismos postcoloniales: CHATterJeE, Partha: Nationalist Thought and the Colonial World Londres 1986 y ColEman, James: Nationalism and Development in Africa Berkeley 1994. De menor peso pero interesante para ver la relación entre género, cuerpo y poscolo-

Hispania, LXI/3, núm. 209 (2001) 933-964 
migenio europeo. Esto, que en cierta medida se hallaba ya en Anderson (cuando afirmaba que las primeras naciones/nacionalismos habían surgido en América), ha sido desarrollado por estudiosos de la talla de Homi K. Bhabha ${ }^{95}$ (cuyos análisis habrán de influir aún mucho las futuras investigaciones) o Partha Chatterjee ${ }^{96}$. El hibridismo, las identidades problemáticas, las influencias que el propio hecho colonizador ha tenido sobre la «madre patria» son también preocupaciones de esta corriente ${ }^{97}$, que, en cierta medida, son compartidas por buena parte de la nueva investigación sobre nacionalismo.

\section{TERCER NIVEL: CONTESTACIÓN}

El establecimiento de un determinado consenso - de un nuevo paradigma por usar la terminología de Kuhn - lleva consigo el obligado nacimiento de disidencias o contestaciones que, si al cabo de tiempo se multiplican y se hacen lo suficientemente fuertes, conducirán a una nueva propuesta. Hasta ahora la contestación al modelo llamado a veces "modernista»"98 no ha logrado establecerse. Aportaciones relevantes son las de Llobera, Hastings y el ethnosimbolismo propugnado por Anthony $\mathrm{D}$. Smith aunque la mayor línea de resistencia contra el modernismo parece surgir en los países del Este de Europa.

Ya hemos visto como el origen de buena parte de los estudios fundamentales del tema (desde Kohn a Gellner pasando por Hroch) se halla en la parte más centrooriental del continente. Durante el período socialista la tradición nacionalista - y de investigación del tema - no sólo no se interrumpió sino que, contrariamente a la creencia occidental, se intensificó. El efecto de nationbuilding de los regímenes comunistas fue muy elevado - hasta el punto de que puede decirse sin ningún temor que muchas naciones esteuropeas fueron realmente construídas por dichos regímenes- Al mismo tiempo la práctica del sistema fue tal que, mientras que, en general, manifestaciones de tipo liberal, revisionista o izquierdista fueron perseguidas sin piedad, el análisis de la nación y el nacionalismo constituían un refugio de libertad intelectual para muchos intelectuales más o menos disconformes. Siempre y cuando, claro, que se man-

\footnotetext{
nialismo puede verse PURI, Jyoti: Woman, body, desire in post-colonial India : narratives of gender and sexuality, Nueva York 1999.

95 BHABHA, Homi K. (Ed.) Nation and Narration, Londres, Nueva York 1990, o BHABHA, : The Location of Culture, Londres, Nueva York 1994.

96 Además del ya citado, véase CHATterjeE,: The Nation in its Fragments: Colonial and Postcolonial Histories, Princeton 1993.

97 Ejemplos de todo ello en los artículos contenidos en MURRAY, Stuart (Ed.) Not on any Map. Essays on Postcoloniality and Cultural Nationalism, Exeter 1997.

${ }_{98}$ Con dos intenciones, una, como mera descripción de su principal aportación, la nación como un fenómeno moderno, pero otra, menos evidente, como una cierta difamación y un ataque, bastante claro en Hastings, Llobera e incluso, con matices, en Smith.
}

Hispania, LXI/3, núm. 209 (2001) 933-964 
tuvieran dentro de unos ciertos límites: no criticar a la Unión Soviética ${ }^{99}$ y no criticar el socialismo, aunque muchas veces bastaba con no referirse a él. Por todo ello, la situación cultural - y política - después de la transformación del sistema, deja campo libre para un retorno del esencialismo, aunque en los trabajos de una Antonina Klosklowska ${ }^{100}$, por ejemplo, existan novedades importantes.

La disidencia científicamente más sólida es, a mi juicio, la de Anthony D. Smith, siempre y cuando se pueda considerar su trabajo como una divergencia de un modelo que surgió cuando Smith ya había publicado textos sustanciales ${ }^{101}$. Lo aceptamos así porque, desde hace ya tiempo, es el propio Smith el que viene ofreciendo sus teorías como una alternativa a Gellner y Anderson ${ }^{102}$, agrupándolas bajo el epígrafe de etno-simbolismo bistórico ${ }^{103}$.

Podríamos decir que Smith se localiza conscientemente en el centro de la discusión, teniendo a la izquierda a los constructivistas (modernistas, para él) y a la derecha a los esencialistas (perennialistas, en su terminología) ${ }^{104}$. Si bien ha realizado importantes críticas a los trabajos de los modernistas no desdeña sus aportaciones y, de hecho, las utiliza matizadamente. Según él, los modernistas ven la nación como obra de "gastrónomos", que combinan diversos elementos para crear naciones de la nada, es decir en un intervalo temporal corto, referido siempre a los cambios producidos por la modernización. Los perennialistas, por otro lado, contemplan al fenómeno nacional como algo natural, perenne, que se extiende además "geológicamente», como una serie de capas históricas similar a la deposición de estratos en el subsuelo, lo que implica también una cierta lentitud y duración ${ }^{105}$.

$99 \mathrm{Y}$ a veces incluso ni eso, como el caso rumano o determinados sectores del partido en Polonia. (Moczar, los "partisanos»..)

100 Véase sobre todo KıOSKOwSKA, Antonina: Kultury narodowe $u$ korzeni, Varsovia 1996, y, por citar alguno de sus trabajos en inglés, «Neighbouring cultures: some aspects of difficult historical neighbourhoods»: International Sociology $1 / 1992$ y «National identification and the transgression of national boundaries»: Dialogue and Humanism 4/1993, pp. 5-17.

101 SMITH, Anthony D., (Ed.): Nationalist Movements, Londres 1976; ibid. Nationalism in the $20^{\text {th }}$ Century, Oxford 1979; ibid., The Ethnic Revival in the Modern World, Cambridge 1981; ibid., Theories of Nationalism, Londres 1983.

102 SMITH, A.D., "The Myth of the 'Modern Nation' and the Myths of Nations» en Etbnic and Racial Studies 1988/1: 1-26 y Nationalism and Modernism: A Critical Survey of Recent Theories of Nations and Nationalism, Londres/Nueva York 1998, como crítica de las posiciones modernistas. Para presentación de sus propias teorías cf. The Ethnich Origins of Nations, Oxford 1986, y National Identity, Londres 1991.

${ }_{103}$ Él mismo encuadra a John ARMSTRONG [Nations before Nationalism, Chapel Hill 1982] y a John HuTCHINSON [Modern Nationalism, Londres 1994] dentro de esta corriente.

104 Véase también su "Introduction. 'Ethno-symbolism' and the Study of Nationalism» en SMITH: Mytbs and Memories of the Nation, Oxford 1999, pp. 3-27.

105 Cf. SMITH, «Gastronomy or Geology? The Role of Nationalism in the Reconstruction of Nations» en Nations and Nationalism 1995/1, pp. 3-23.

Hispania, LXI/3, núm. 209 (2001) 933-964 
Smith contrapone a los perennialistas la realidad de la investigación histórica que ha demostrado que buena parte de las características dadas por supuesto en las naciones, no son naturales, sino (re)construídas - lo que comparte con los modernistas. Sin embargo a Hobsbawn y Anderson les critica su incomprensión de la base sobre la que se crean las naciones, el material primigenio, que no es maleable a voluntad de determinadas elites sino sólo «producto de una compleja interrelación entre estos creadores, sus condiciones sociales y la herencia étnica de las poblaciones escogidas» ${ }^{106}$. La nación, según Smith, puede ser una formación social moderna, pero siempre se construye sobre la base de culturas preexistentes y concretos - ineludibles - legados identitarios. Así, el etno-simbolismo histórico surge de la crítica de los enfoques modernistas tanto como de una lectura diferente de las fuentes. «Para los ethno-simbolistas, lo que da al nacionalismo su poder son los mitos, las memorias, tradiciones y símbolos del legado étnico, y las formas en las que un pasado vivido popularmente ha sido, y puede ser, redescubierto y reinterpretado por las modernas intelligentsias nacionalistas» ${ }^{107}$.

En suma, lo que Smith propone - después de caricaturizar en buena medida teorías de lo que hemos dado en llamar «el nuevo consenso»- es una mayor atención a las profundidades de las persistencias «étnicas» - dándole un sentido un poco confuso al término- y una visión de longue durée de la formación de las naciones. Sin embargo y a mi modo de ver, no hay en su análisis nada que contradiga las aportaciones de Gellner o Anderson y sí mucho que puede ser integrado en una teoría más general o conjunta. El hecho de que las naciones sean construídas no es invalidado por la circunstancia de que, quienes las construyen, se vean limitados por la preexistencia de una determinada realidad etno-histórica - por usar un término suyo-. Que el pasado esté compuesto de tradiciones y memorias constantemente reelaboradas, no impide que sea sólo el profundo choque de la llegada de la modernidad lo que permita la creación de naciones en el sentido actual.

Una de los temas centrales del etno-simbolismo es, según Smith, «la relación de las memorias compartidas con la identidad cultural, y el cultivo de dichas memorias es esencial para la supervivencia de tales identidades colectivas» ${ }^{108}$. Esto acerca sus teorías a la reciente preocupación de las historiografías - y la opinión pública ${ }^{109}$ - centroeuropeas por el fenómeno de la memoria

\footnotetext{
106 SMITH: Myths and Memories of the Nation, Oxford 1999, p. 171.

107 Íbidem: 9.

108 Íbidem: 10.

109 Véanse para el caso alemán las frecuentes discusiones y los debates públicos en temas como la singularidad del holocausto (el Historikerstreit), la participación de los alemanes en el nazismo, (el debate Goldhagen) o la más reciente en torno a la construcción en Berlín de un enorme monumento a los judíos exterminados. Véanse VVAA: Historikerstreit. Die Dokumentation der Kontroverse um die Einzigartigkeit der nationalsozialistischen Judenvernichtung, Munich / Zürich 1987, SCHÖPS, Julius H.: Ein Volk von Mördern? Eine Dokumentation zur Goldhagen-Kontroverse um die Rolle der Deutschen in Holocaust,
} 
histórica o colectiva (kollektives Gedächtnis). Parece claro que, sobre todo en Alemania, esta tendencia tiene mucho que ver con los problemas de asunción del pasado dentro de un nuevo espacio social colectivo que es, por primera vez, verdaderamente nacional ${ }^{110}$. En cierta medida todas estas investigaciones están situadas al margen de los aportes de Anderson y Gellner — sin llegar a ser críticas directas-, aunque también se benefician de la ampliación de temas y enfoques de las últimas décadas.

La base teórica sustancial ha sido pergeñada por Alaida y Jan Assman, quienes - aunque con intereses ligeramente distintos- ofrecen a través de sus obras una sistemática y profunda revisión del concepto de memoria colectiva. Jan Assman ha intentado, principalmente a través del análisis de las culturas de la antigüedad ${ }^{111}$, establecer las diferencias entre «la memoria comunicativa», propia de la vida cotidiana, y la «memoria cultural», que supone la objetivización de elementos culturales y, por tanto, la transmisión de conocimiento entre unas generaciones y otras ${ }^{112}$.

Sobre esta base teórica - aunque con aportes y tradiciones muy distintas y plurales - se han multiplicado las obras que analizan y valoran esta «memoria colectiva», no entendida, en principio, dentro de una perspectiva esencialista, aunque basculando inadvertidamente hacia ella. Resulta interesante comprobar a través de algunas publicaciones concretas - producto a veces de proyectos conjuntos de investigación - como, en este tema, las historiografías de la zona parecen haber entrado en un proceso de confluencia ${ }^{113}$.

Un trabajo de matiz muy distinto y que, sin embargo, podemos situar dentro de la perspectiva de Smith es el de Josep R. Llobera. Voluntariamente crítico con el modernismo, Llobera comprende la identidad nacional, el «nacionalismo patriótico" y el propio fenómeno de la nación como un proceso de longue durée y traza su comienzo en la Edad Media - para el caso de Europa Occiden-

\footnotetext{
Hamburgo 1996. El caso polaco, por ejemplo, se puede ilustrar con la creación del «Instituto de la Memoria Nacional», institución cuya principal misión es la de hacer luz sobre los abusos de la época socialista, aunque continúa también una similar tradición de posguerra relacionada con la memoria de la ocupación hitleriana. En Rusia, uno de los principales movimientos de oposición de la perestroika - aún activo- se llamaba Pamiat' (Memoria) y demandaba el recuerdo y la rehabilitación de las víctimas del stalinismo. (No confundir con el grupúsculo de extrema derecha del mismo nombre).

110 Sobre estos problemas puede verse SCHULTZ, Helga: «La nación tras el diluvio. Una perspectiva germano-oriental» en Cuadernos de Historia Contemporánea, Madrid, 22 (2000): 303-324.

111 Su obra más importante es Das kulturelle Gedäcbtnis. Scbrift, Erinnerung und politische Identität in früben Hocbkulturen, Munich 1992.

112 Véase ASSMAN, Jan: «Kollektives Gedächtnis und kulturelle Identität» en ASSMAN, Jan / HÖLSCHER, Tonio (Eds.): Kultur und Gedächtnis, Frankfurt/Main 1988, pags. 9-19.

113 Puede verse TOPOLSKY, Jerzy (Ed.): Historisches Bewusstsein und politisches Handeln in der Geschichte, Poznan 1994; BRIX, Emil / STEKL, Hannes (Ed.): Der Kampf um das Gedächtnis. Öffentliche Gedenktage in Mitteleuropa, Viena 1997, y el muy interesante KOBYLIÑSKA, Ewa / LAWATY, Andreas (Eds.): Erinnern, vergessen, verdrängen. Polnische und deutsche Erfabrungen, Wiesbaden 1998, que contiene un artículo de Alaida Assman donde se percibe claramente la tentación esencialista.
} 
tal $^{114}$. El libro es en verdad excelente, su revisión del material historiográfico es de primer orden y a su concepción del nacionalismo como «secularizado dios de nuestros días" no hay mucho que objetar. Sin embargo su insistencia en la crítica al modernismo resulta un tanto peculiar, habida cuenta de que su análisis no contradice en general nada de lo propuesto por Gellner y compañía. El hecho de que las naciones se construyan sobre la base de un corpus cultural preexistente no invalida que sólo vengan a existir cuando se den las condiciones adecuadas, el hecho de que grupos concretos en el pasado, ciertas elites, desarrollaran un sentimiento de ligazón con una simbología territorial que podemos muy bien definir como "patriotismo", no impide que el nacionalismo, tal y como lo entendemos, como fenómeno de masas y relacionado con una aspiración de poder del demos, sea un fenómeno absolutamente moderno.

Una aparente confirmación de las tesis de Llobera se encuentra en los trabajos de Wolfgang Hardtwig quien, aunque con menos amplitud -por centrarse sólo en el caso alemán - ha buscado - y encontrado - nacionalismo en las actitudes y las mentalidades de las élites alemanas desde el siglo $\mathrm{XV}^{115}$. Su obra, desde la perspectiva de la historia cultural y de las ideas, reclama la diferenciación entre una «conciencia nacional de las élites» y un «movimiento de masas». No parece muy claro sin embargo cual sea la ligazón entre los pensadores humanistas (en cuyas obras, ciertamente, resulta posible encontrar poderosas afirmaciones de patriotismo avant la lettre) y el nacionalismo alemán posterior a la invasión napoleónica. ¿Acaso ese hilo no podría ser sino una construcción de la propia mitología nacional del siglo XIX? Parece sin embargo cierto que hay una cierta verdad en la imagen de esos solitarios patriotas de unas naciones que aún no existen, escribiendo para un público que ellos anhelan más amplio que el de una mera corte medieval ${ }^{116}$. Sin embargo, por citar una muy citada frase de Michel Maurer, la Edad Moderna («frühe Neuzeit») «termina allí donde la identidad social y confesional cesan de ser dominantes y se disuelve en un nuevo tipo de identidad: la nacional» ${ }^{117}$.

La afirmación de la modernidad de las naciones que tanto molesta a Llobera, apenas afecta a otro investigador, el politólogo Walker Connor, quien afirma que «lo que cuenta al fin y al cabo no es lo que es sino lo que la gente cree que

114 Véase LLOBERA, Josep R: The God of Modernity, The Development of Nationalism in Western Europe, Oxford/Providence 1994. Un artículo interesante - si bien en un tono algo más politológico- LLOBERA, J. R.: «The Future of Ethnonations in a United Europa» en WICKER, Hans Rudolf. (Ed.): Rethinking nationalism and Ethnicity. The Struggle for Meaning and Order in Europe. Oxford 1997, p. 43-55.

115 HARDTWIG, Wolfgang: Nationalismus und Bürgerkultur in Deutschland 1500-1914, Göttingen 1994.

116 Podríamos referirnos también a un Quevedo para el caso español, por ejemplo.

117 MAURER, Michael: «'Nationalcharakter' in der frühen Neuzeit. Ein mentalitätsgeschichtlicher Versuch», en BlomerT, Reinhart / KuZMics, Helmut / TREIBEL, Annette (Eds.): Transformationen des Wir-Gefübls. Studien zum nationalen Habitus, Frankfort/Main 1993, pp. 45-81, aquí p. 81.

Hispania, LXI/3, núm. 209 (2001) 933-964 
es» ${ }^{118}$. En sus trabajos encontramos una provocativa y vibrante crítica al concepto de Estado nacional y, al mismo tiempo, una etnificación del propio concepto de nación. Autor de una serie de muy citados artículos a lo largo de los años sesenta y setenta —que, sorprendentemente, sólo serían recogidos en forma de libro en los años noventa- y de un voluminoso y excelente análisis de las relaciones entre nacionalismo y marxismo ${ }^{119}$, Connor se muestra extremadamente crítico de esencialismos de cualquier tipo y de la identificación de nación con Estado. Nación y etnia son, en su opinión, sinónimos y todo nacionalismo es un etnonacionalismo cuya misión es la destrucción de todo Estado existente (puesto que, según él, sólo un puñado de Estados en el mundo son verdaderos Estados-nación). Estados que no se definen étnicamente —como Norteamérica — son para él la excepción y el camino de la globalización no sirve para unificar sino que, antes al contrario, extiende el virus de la autoidentificación y, por tanto, del etnonacionalismo.

Aunque del todo correctas, las apreciaciones de Connor tienden a olvidar el poder nacionalizador - homogeneizador - del Estado, magnifican la perdurabilidad de las identidades y su homogeneidad y conceden una importancia, a nuestro juicio excesiva, a la competencia de lealtades políticas. Sus análisis, sin embargo, son frescos, a contracorriente, y ponen en cuestión tanto las convenciones esencialistas del nacionalismo como el propio consenso modernista (aún encuadrándose en cierta medida dentro de él).

La aportación bastante reciente de Adrian Hastings ${ }^{120}$ es lo suficientemente citada en los últimos tiempos como para que la comentemos aquí, pese a su poco ética y constante toma de partido, sus distorsiones de ideas con las que no comulga y su irritante revoltijo de frases excelentes y absurdas contradicciones. El libro de Hastings es voluntariamente un anti-Hobsbawm, y no sólo porque se compone de las conferencias impartidas en el mismo lugar que las que, casi diez años antes, acabaron por formar el Nations and Nationalism de Hobsbawm. El propio Hastings declara que su intención es la de rebatir las asunciones de aquel, y de paso, las de muchos otros de los modernistas. La suposición principal del libro es que en el estudio del nacionalismo se ha menospreciado el papel de la religión - y de la Biblia, que según él presenta una descripción primordial de una nación con todas las características modernas-, lo que, en gran medida es cierto. Pero el hecho es que Hastings tampoco consigue explicar satisfactoriamente cual es el nexo original entre nación y religión.

Más aún. El caso primigenio y prototípico de nación y nacionalismo es, para él, Inglaterra, cuyo nacionalismo remonta hasta el siglo IX (!!), haciendo retroceder al fenómeno nacional hasta el medievo ${ }^{121}$. Inglaterra no es sólo la primera nación de la historia, es también el origen de todas las demás porque

118 Véase: CONNOR, Walker: Ethnonationalism. The Quest for Understanding, New Jersey 1994. Aquí citamos la página 93.

119 CONNOR, W.: The National Question in Marxist-Leninist Theory and Strategy Princeton 1984.

120 HaStings, Adrian: The Construction of Nationbood, Cambridge 1997.

121 Ibidem..., p. 5. 
el resto de estados y grupos étnicos, ante el éxito y el aparente poder de la nación inglesa, optaron por seguir el ejemplo ${ }^{122}$. Hay de nuevo algo de verdad en ello, ya que el modelo de democracia y de industrialización inglés ejerció un evidente atractivo sobre numerosas elites europeas del siglo XVIII y XIX. Y sin embargo esto sólo nos trae de nuevo al modelo gellneriano que él critica ásperamente, afirmando que «la comprensión de las naciones y del nacionalismo sólo avanzará cuando cualquier ligazón inseparable entre ellos y la modernización de la sociedad sea abandonada» ${ }^{123}$.

Asímismo Hastings plantea una serie de problemas interesantes - como el de la extensión en la cual la literatura oral puede ser un medio de creación de la autoimagen de un pueblo ${ }^{124}$ - que, sin embargo no analiza, ni explora, ni siquiera intenta aclarar. En resumen, se trata de un intento fallido de realizar una crítica fundamental del paradigma reinante.

Recapitulando, podríamos decir que los trabajos que se oponen a la versión modernista del nacionalismo, si bien han señalado matices muy importantes y planteado preguntas y problemas nuevos, no han conseguido romper con el consenso. Estas aportaciones, es cierto, suponen un excelente correctivo contra la tendencia de explicar - otra vez- teleológicamente el nacionalismo, ahora como inevitable subproducto de la modernidad, pero ello no les impide caer — salvo en el caso Smith- en el esencialismo más o menos disimulado.

\section{ALGUNOS FRAGMENTOS}

Aunque hemos mostrado las corrientes principales de investigación sobre el tema, hay una importante cantidad de trabajos que no pueden ser encuadrados dentro de ninguna de ellas. Son los restos de la academia o, por así decirlo, sólidos trabajos empíricos cuya intención es mostrar y defender alguna tesis concreta de nivel secundario. No podemos reseñar todos estos libros pero no podemos tampoco dejar de mencionarlos, dado que algunos de ellos resultan fundamentales. Muchos de ellos son producciones de historia de las ideas como las de Andrzej Walicki, quien ha dedicado muchos libros al análisis de las ideas marxistas y socialistas en Rusia, pero es también el autor de un buen número de trabajos sobre nacionalismo en Rusia y Polonia ${ }^{125}$. Los trabajos de Roman

\footnotetext{
122 Ibidem..., p. 8.

123 Ibidem..., p. 9

124 Ibidem..., p. 23.

125 WALICKI, Andrej: The Enlightenment and the Birth of Modern Nationbood: Polish Political Thought from Noble Republicanism to Tadeusz Kosciuszko, Notre Dame 1989; ibid. The Slavophile Controversy: History of a Conservative Utopia in. Nineteenth-Century Russian Thought, Notre Dame 1989 [1975], ibid. Philosophy and Romantic Nationalism, Notre Dame 1994.
}

Hispania, LXI/3, núm. 209 (2001) 933-964 
Szporluk ${ }^{126}$, de John Dunlop ${ }^{127}$, de Timothy Snyder ${ }^{128}$ o, en parte, el libro de Payne sobre el fascismo ${ }^{129}$, podrían entrar también dentro de este epígrafe.

Otro aspecto del nacionalismo que está siendo revisado con provecho es el nacionalismo económico aunque, de nuevo, la perspectiva esteeuropea es de contestación al modelo occidental ${ }^{130}$. Jan Kofman, en su celebrado libro, presenta el nacionalismo económico de entreguerras en una luz mucho más positiva de lo acostumbrado, describiéndolo como una importante oportunidad de crecimiento para países económicamente atrasados ${ }^{131}$. Estudios de casos concre$\operatorname{tos}^{132}$ y perspectivas comparativas ${ }^{133}$ han enriquecido también el tratamiento de un tema al que, un análisis de tono más culturalista, ha permitido producir obras de una riqueza y una ambigüedad mucho mayores ${ }^{134}$.

El estudio del fascismo y del antisemitismo (temas que no son, por supuesto, lo mismo que el nacionalismo pero que históricamente han estado íntimamente ligados a él) ha recibido renovada atención en los últimos años. Desde el libro famoso de Goldhagen ${ }^{135}$ hasta la reconstrucción de la actividad de partidos nacionalistas antisemitas en los países del este ${ }^{136}$, se ha desarrollado, haciendo hincapié en aspectos previamente olvidados, toda una nueva visión del fenómeno que agitó Europa durante la primera mitad del siglo XX. A este respecto con-

126 SzPORLuK, Roman: The political thought of Thomas G. Masaryk, Boulder 1981; ibid. Comunism and Nationalism. Karl Marx versus Friedrich List, Nueva York 1988 o su reciente: Russia, Ukraine, and the breakup of the Soviet Union, Stanford 2000.

${ }_{127}$ DuNLOP, John: The Faces of Contemporary Russian nationalism. Princeton 1983 y ibid. The Rise of Russia and the Fall of the Soviet Empire Princeton 1995.

128 SNYDER, Timothy: Nationalism, Marxism and Modern Central Europe: a Biography of Kazimierz Kelles-Krauz (1872-1905), Cambridge 1997.

129 PAYNe, Stanley G: : A History of Fascism, 1914-1945, Madison 1995.

${ }_{130}$ Cuyo máximo exponente son las tesis de HeIlPerin, Michael A.: Studies in Economic Nationalism, Ginebra/París 1960, en torno a la relación entre totalitarismos y nacionalismo económico.

131 Véase Kofman, Jan: Nacjonalizm gospodarczy - szansa czy bariera rozwoju?, Varsovia 1992, edición inglesa: KofmAN, J.: Economic Nationalism and Development: Central and Eastern Europe between the two World Wars, Boulder, Col. 1997.

132 KÖLL, Anu Mai, JAAK, Valge: Economic Nationalism and Industrial Growth: State and Industry in Estonia 1934-1939, Estocolmo 1998. Este libro resulta además interesante porque presenta las dos perspectivas, occidental y esteeuropea, sin decidirse por ninguna de ellas.

133 SZLAJFER, Henryk (Ed.): Economic Nationalism in East-Central Europe and South America 19181939, Ginebra 1990 o ETGES, Andreas: Wirtschaftsnationalismus: USA und Deutschland im Vergleich (1815-1914), Francfort/ Nueva York 1998.

134 Véase por ejemplo el excelente estudio de JAwORSKI, Rudolf: Handel und Gewerbe im Nationalitätenkampf: Studien zur Wirtschaftsgesinnung der Polen in der Provinz Posen (1871-1914), Göttingen 1986.

135 GoldHAGEN, Daniel Jonah: Hitler's Willing Executioners: Ordinary Germans and the Holocaust, Nueva York 1997.

136 BergmanN, Olaf: Narodowa Demokracja wobec problematyki zydowskiej w latach 1918-1929, Poznan 1998 y LANDAU-CZAJKA, Anna: W jednym stali domu ... Koncepcje rozwiazania kwestii zydowskiej w publicystyce polskiej lat 1933-1939 Varsovia 1998. 
vendría citar también los trabajos de Götz $\mathrm{Aly}^{137}$, quizá el más vibrante y agudo investigador actual del tema.

En cualquier caso parece cada vez más difícil realizar un análisis empírico sobre el nacionalismo que evite tener en cuenta los parámetros teóricos definidos por el paradigma del modernismo. Todo lo más se le puede negar por completo, diciendo que aquí no ha pasado nada y volviendo a escribir como si todavía fuera posible mantenerse dentro del paradigma de la historiografía nacional del siglo XIX. Resulta por demás curioso que a algo de esto tienden determinados ex-miembros del movimiento del sesentayocho alemán - y no sólo de él-, quienes aspiran a poder volver al cómodo y seguro nicho nacional y académico. Por el contrario la situación en los países de Europa Central, especialmente en las generaciones más jóvenes, es muy distinta. Más que un retorno del academicismo o del historicismo - algo que constituyó el refugio de todo científico honrado durante el período del dogmatismo oficial comunista-, lo que ha aparecido - entre otras muchas cosas - es un puñado de jóvenes y airados historiadores fascistoides o nacionalistas de nuevo cuño, que reivindican las tradiciones de la nouvelle droite, e intentan a toda costa crear una visión historiográfica nacionalista pero también europeísta —en su sentido más negativo-.

Quizá por ello, la crítica al modernismo - y al posmodernismo-, que proviene de extremos tan dispares, cumpla una función de nuevo política o politizada. Aunque, por supuesto, para muchos autores se mantiene dentro de los límites de la reflexión intelectual pura —si algo así existe-, es difícil comprender el apasionamiento de muchos de los críticos si no tomamos en cuenta consideraciones ajenas al propio problema a discutir.

\section{CONCLUSIONES}

Como afirma Craig Calhoun en un clarificador análisis general del tema, el nacionalismo «es una retórica para hablar sobre demasiadas cosas diferentes como para que una sola teoría lo explique» ${ }^{138}$. Por esta razón la actual pluralidad de estudios no puede ser más que beneficiosa. Integrar el nacionalismo en una teoría general del desarrollo humano - titánica tarea realizada con sorprendente facilidad por Ernest Gellner - requiere de un determinado instrumental histórico que es muy distinto del que precisará, por ejemplo, el análisis del proceso por el que ciertos mitos políticos y tradiciones culturales adquieren un determinado sentido y acaban por integrar el corpus de imágenes de una nación - empresa de Anthony D. Smith o de Josep R. Llobera-. No se trata

137 ALY, Götz / HeIm, Susanne: Vordenker der Vernichtung. Auschwitz und die deutschen Pläne für eine neue europäische Ordnung, Francfort/Main 1995. y ALY, G.: «Endlösung». Volkverschiebung und der Mord an den europäischen Juden, Francfort/Main 1995. Una de sus publicaciones en inglés: Cleansing the Fatherland: Nazi Medicine and Racial Hygiene, Baltimore 1994.

138 CalHoun, Craig: Nationalism, Buckingham 1997, p. 8.

Hispania, LXI/3, núm. 209 (2001) 933-964 
de eclecticismo barato, sino de adecuar los medios al fin y de delimitar correctamente las características peculiares de procesos relacionados, pero no idénticos.

Entre la jungla de estudios contemporáneos podemos discernir pasos en esta dirección, al tiempo que apuntan algunos nuevos/viejos fenómenos. Parece haber un retorno hacia el escudriñamiento de la nación desde un punto de vista de sus fundamentos más materiales. La reactualización de Deutsch o de Chlebowczyk parece indicar que, al menos en Europa, se ha pasado del «momento de la historia social al trabajo de la representación cultural» ${ }^{139}$, para acabar regresando al análisis social, si bien ahora enriquecido con la aportación culturalista, y mostrándose mucho menos ingenuo en sus premisas que la historia social de la época de la guerra fría.

139 ELEY / SUNY (Eds.) Becoming National... p. 3.

Hispania, LXI/3, núm. 209 (2001) 933-964 